chemistry will find the book a most instructive and suggestive one.

In matters of detail some criticisms will occur to the reader. For example, the quantitative experiments on the composition of water and on the weight of hydrogen displaced by a given weight of magnesium give, in the hands of beginners, results so inaccurate that their usefulness is thereby largely destroyed. Again it is unfortunate that arbitrary words like hydrogenion, cupricion, and leadion should be employed when a logical system like Walker's is already in use by chemists. But these details do not materially obscure the very prorounced merits of the book.

A. $\mathrm{S}$.

The Chemistry of Paints and Paint Vehiches. By Crare H. Hall,

B.S. New York: D. Van Nostrand Co. Ig06. I 34 pp. Price, $\$ 2.00$.

This is a book written by a chemist engaged in the manufacture of paints and colors, and gives what, in the judgment of the author, are the best methods for determining the various substances which practically occur in ordinary paints. As a rule only one method is given for each sulsstance, and a good norking knowledge of analytical methods is assumed. The book would be better if more details were given, or if there were references to standard works; but on the whole it may be said that the book is useful, indeed valuable, to any one engaged in such work. Probably any other chemist will believe some method not given here better than the one given; but by being rigidly confined to one method for each substance, the book is made compact and intelligible. In the judgment of the reviewer, some valuable methods are omitted, e. g., McIlhiney's method for separating turpentine, etc., and the use of the polariscope and refractometer in detecting adulterations in liquids; also Langmuir's method for shellac. On the whole, the book is a gccd bcok and would be better if there were more of it. The most common failing of the specialist is that of forgetting that what is well-known to hin is not familiar to his readers; because no book is written for specialists only.

A. H. SABIN.

\title{
RECENT PUBLICATIONS.
}

Eifectrochemistry OF ORGaNIC Compounds. By Walther Löb. Trans. from the author's enlarged and revised third edition by H. W. F. Lorenz. New York: J. Wiley \& Sons. rgo6. Io +308 pp. $\$ 3.00$. 